\title{
Discovery of small molecule bioactive agents from endophytic fungi of the Sonoran Desert
}

\author{
B.P. BASHYAL ${ }^{1}$, A.M. BURNS ${ }^{1}$, M.X. LIU ${ }^{1}$, P. A. PARANAGAMA ${ }^{1}$, C.J. SELIGA ${ }^{1}$, T. J. TURBYVILLE ${ }^{1}$, E.M.K. \\ WIJERATNE ${ }^{1}$, J. ZHAN ${ }^{1}$, M.K. GUNATILAKA ${ }^{2}$, A.E. ARNOLD ${ }^{2}$, \\ S.H. FAETH ${ }^{3}$, L. WHITESELL ${ }^{4}$ and A.A.L. GUNATILAKA ${ }^{1}$ \\ ${ }^{\prime}$ Southwest Center for Natural Products Research, Office of Arid Lands Studies \\ ${ }^{2}$ Division of Plant Pathology, Department of Plant Sciences, College of Agriculture \& Life Sciences, University of Arizona, 250 E. \\ Valencia Road, Tucson, Arizona 85706-6800, USA \\ ${ }^{3}$ School of Life Sciences, Arizona State University, Tempe, Arizona \\ ${ }^{4}$ Whitehead Institute, Massachusetts Institute of Technology, Boston, Massachusetts, USA
}

leslieg@ag.arizona.edu

\begin{abstract}
In our search for novel small molecule bioactive agents from endophytic fungi of the Sonoran desert, extracts derived from cultures of some selected endophytic fungal strains have been screened in assays for inhibition of heat shock protein 90 (Hsp90) activity, cancer cell proliferation and migration. Chaetomium chiversii, Chaetomium globosum, Fusarium acuminatum and Fusarium oxysporum producing metabolites active in these assays were cultured on large-scale and the derived extracts were subjected to bioactivity-guided fractionation to obtain a variety of natural products with diverse structures, and potential applications in cancer chemotherapeutics. This paper discusses the isolation, characterisation, and biological activity of some selected small molecule metabolites.

Keywords: endophytic fungi, small molecule natural products, isolation, structure elucidation biological activity, cytotoxic agents, cell migration inhibitors; Hsp90 inhibitors
\end{abstract}

\section{Introduction}

The growing body of evidence suggests that endophytic microorganisms represent a huge and largely untapped resource of small molecule natural products with chemical structures that have been optimised by evolution for biological and/or ecological relevance. In their symbiotic association, the macrophyte protects and feeds the endophyte, which 'in return' produces bioactive compounds to enhance the growth and competitiveness of the host and to protect it from herbivores and plant pathogens. Accordingly, some endophytes could be valuable sources of biologically active small molecule metabolites including anticancer agents. This is exemplified by isolation of anticancer drugs such as Taxol ${ }^{\mathrm{TM}}$ (paclitaxel) (Stierle et al. 1993; Stierle et al. 1995; Strobel et al. 1996), camptothecin (Puri et al. 2005),

Figure 1 Metabolites of Chaetomium chiversii.

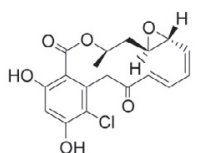

Radicicol (1)<smiles>C=C/C=C/c1cc2c(Cl)c(O)cc(O)c2c(=O)o1</smiles>

Chaetochiversin B (3)

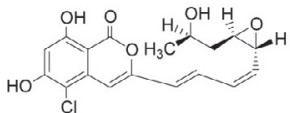

Chaetochiversin A (2)

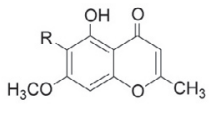

$\mathrm{R}=\mathrm{CH}_{3}$; Eugenetin (4)

$\mathrm{R}=\mathrm{CH}_{2} \mathrm{OCH}_{3}$; 6-Methoxymethyleugenin (5)

$\mathrm{R}=\mathrm{CH}_{2} \mathrm{OH} ; 6$-Hydroxymethyleugenin (6) and podophyllotoxin (Eyberger et al. 2006) from endophytic fungal strains.

The possibility that plant-associated microbial diversity is influenced by the diversity of plant species and environmental factors suggests a greater potential for harvesting unique secondary metabolites from endophytic microorganisms found in association with hitherto unexploited floristically diverse plant communities (Gunatilaka 2006). Until now most studies on endophytes of higher plants for bioactive agents have focused on those that occur in northern temperate forests. Adaptations of endophytic communities in plants that grow in extreme habitats, other than arctic or alpine plants, are generally unknown. Desert plants have largely been ignored as a source of endophytes probably due to the assumption that endophyte infection requires humidity. Contrary to this contention, Faeth and co-workers have recently isolated and partially identified over 400 endophytic fungal taxa from Arizona fescue (Schulthess \& Faeth 1998), more than 40 morphospecies of endophytic fungi from Emory oak (Faeth \& Hammon 1997) and 22 endophyte species from cacti (Suryanarayanan et al. 2005) growing in very dry regions of Arizona. It is noteworthy that endophytically established fungi, such as Hypoxylon spp. undergo active mycelial development in response to water stress in host organs (Chapela 1989). Even endophytes in agronomic grasses grown under mesic conditions produce metabolites that increase resistance to drought stress (Clay \& Holah 1999; Bush et al. 1997). It is reasonable to expect that endophytes in plants in xeric habitats should produce even greater diversity of these metabolites.

In our search for novel small molecule bioactive agents from endophytic fungi of the Sonoran desert, we have constructed an endophytic fungal library consisting of over 1000 strains. Extracts derived from cultures of over 600 of these have been screened in assays for inhibition of heat shock protein 90 (Hsp90), cancer cell

Figure 2 Metabolites of Chaetomium globosum.

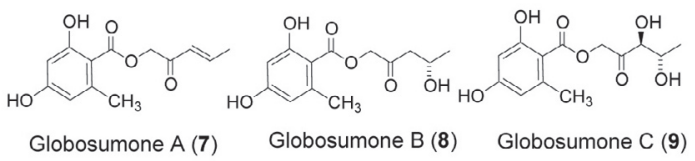<smiles>Cc1cc(O)cc(O)c1C(=O)O</smiles>

Orsellinic acid (10)

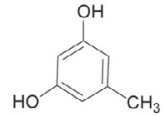

Orcinol (11)

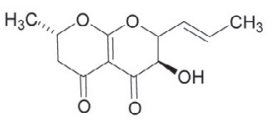

Trichodion (12) 
Figure 3 Metabolites of Fusarium acuminatum.

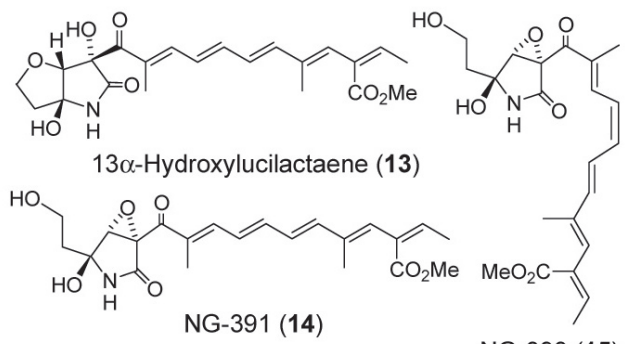

NG-393 (15)

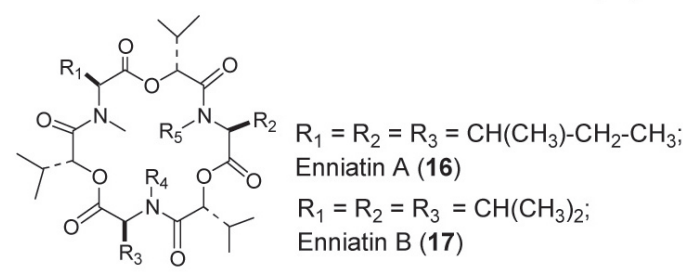

proliferation, and migration. Organisms producing metabolites active in these assays were identified, cultured on large-scale and the derived extracts have been subjected to bioactivity-guided fractionation to obtain a variety of natural products with diverse structures, and potential applications in cancer chemotherapeutics. Presented herein are results obtained for four endophytic fungal strains inhabiting plants of the Sonoran desert.

\section{Results and Discussion}

\section{Metabolites of Chaetomium chiversii}

For the discovery of small molecule natural product inhibitors of Hsp90 with potential anticancer activity, we developed a strategy involving: (a) a primary moderate-throughput phenotypic screen using the cellular heat shock response as monitored by enhanced green fluorescent protein (EGFP) expression as the endpoint (Heat Shock Induction Assay; HSIA); and (b) a low-throughput but well characterised secondary assay for direct inhibition of chaperone activity involving the ATP-dependent refolding of heat-denatured luciferase (luciferase-refolding assay; LRA). These assays were used to identify active extracts and to guide their subsequent fractionation to yield pure compounds. Using this approach, we have evaluated ethyl acetate extracts derived from over 500 Sonoran desert plant-associated endophytic fungal strains. Several extracts active in both primary and secondary assays were encountered. One such extract was derived from Chaetomium chiversii (Chaetomiaceae) endophytic on the stem tissue of Mormon tea (Ephedra fasciculata A. Nels.; Ephedraceae). HSIA-guided fractionation of the ethyl acetate extract of $C$. chiversii afforded the known Hsp90 inhibitor, radicicol (1) (Fig. 1), as the only active compound of this extract (Turbyville et al. 2006). It is noteworthy that $C$. chiversii has not been subjected to any chemical investigation before our work. This report constitutes the first evidence for the occurrence of radicicol (1) in an endophytic fungus.

Chromatographic fractionation of the non-cytotoxic fraction of the ethyl acetate extract of $C$. chiversii afforded two new isocoumarins, chaetochiversin A(2) and chaetochiversin B (3), and
Figure 4 Metabolites of Fusarium oxysporum.
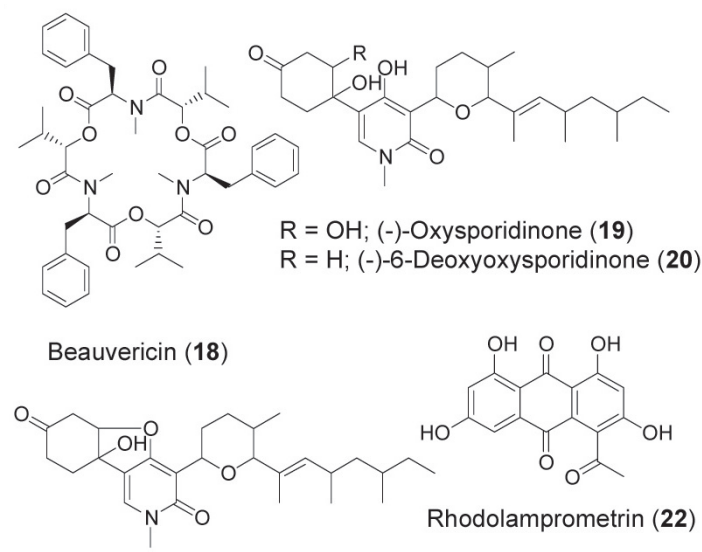

(-)-4,6'-Anhydrooxysporidinone (21)

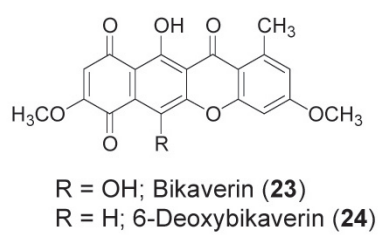

three known chromones, eugenetin (4), 6-methoxymethyleugenin (5), and 6-hydroxymethyleugenin (6) (Fig. 1) (Wijeratne et al. 2006). Co-occurrence of the isocoumarins, chaetochiversins A - B (2 - 3), and the $\square$-resorcylic acid lactone macrolide, monocillin I (1), in this fungal strain suggests that the biosynthesis of monocillin I may involve the intermediacy of these isocoumarins.

\section{Metabolites of Chaetomium globosum}

The cytotoxic ethyl acetate extract of Chaetomium globosum Ames (Ascomycete), occurring in the stem tissue of Mormon tea (Ephedra fasiculata A.; Family - Ephedraceae), on solventsolvent partitioning (Gunatilaka \& Kingston 1998) yielded a bioactive chloroform fraction which on size-exclusion, silica gel and reversed-phase chromatography afforded three new orsellenic acid esters, globosumone A (7), globosumone B (8), and globosumone $\mathrm{C}(\mathbf{9})$, and previously known metabolites, orsellinic acid (10), orcinol (11), and trichodion (12) (Fig. 2). The chemical structures of all new compounds were elucidated by spectroscopic analyses, including two-dimensional nuclear magnetic resonance (NMR) techniques, chemical interconversions and NMR analysis of their Mosher's esters (Bashyal et al. 2005). All compounds were evaluated for in vitro inhibition of cell proliferation using a panel of four cancer cell lines [NCI-H460 (non-small cell lung), MCF-7 (breast), SF-268 (CNS glioma), and MIAPaCa-2 (pancreatic cancer)], and normal human fibroblast (WI-38) cells, and only globosumones A (7) and $\mathrm{B}(\mathbf{8})$ were found to be cytotoxic.

\section{Metabolites of Fusarium acuminatum}

The isolate of Fusarium acuminatum (mitosporic Hypocreales) occurring in the root tissue of Larrea tritentata (creosote bush; Zygophyllaceae) was cultured in potato dextrose broth (PDB) for 
14 days, filtered and the filtrate was extracted with ethyl acetate. Fractionation of the cytotoxic ethyl acetate extract by solventsolvent partitioning (Gunatilaka \& Kingston 1998) caused the activity to partition successfully into the $80 \%$ aqueous methanol phase of hexane- $80 \%$ aqueous methanol and then into the chloroform phase of chloroform-50\% aqueous methanol partition. Further fractionation of the bioactive chloroform fraction by size-exclusion chromatography over Sephadex LH-20 followed by reversed-phase (RP-18) chromatography and normal silica gel chromatography, and preparative thin-layer chromatography afforded a new compound, 13 $\alpha$-hydroxylucilactaene (13) and four known metabolites, NG-391 (14), NG-393 (15), enniatin A (16), and enniatin B (17) (Fig. 3). Compounds 13 - 17 were evaluated for in vitro inhibition of cell proliferation/survival using a panel of five cancer cell lines [NCI-H460 (non-small cell lung), MCF-7 (breast), SF-268 (CNS glioma), and MIAPaCa2 (pancreatic carcinoma), $\mathrm{PC}-3 \mathrm{M}$ (metastatic prostate cancer)], and normal human fibroblast (WI-38) cells; only enniatins A (16) and $\mathrm{B}(\mathbf{1 7})$ were cytotoxic at low micromolar concentrations but with no apparent selectivity.

\section{Metabolites of two strains of Fusarium oxysporum}

Ethyl acetate extracts derived from two endophytic strains of Fusarium oxysporum (mitosporic Hypocreales) inhabiting the root tissue of Ephedra fasciculata (Mormon tea; Ephedraceae) and the stem tissue of Cylindropuntia echinocarpus (silver cholla; Cactaceae) were found to have activity in assays for inhibition of cancer cell migration [wound-healing assay (WHA)] and proliferation/survival [MTT assay]. WHA-guided fractionation of the ethyl acetate extract of a solid culture of $F$. oxysporum strain $\mathrm{EPH} 2 \mathrm{R}_{\mathrm{AA}}$ led to the isolation of beauvercin (18), along with (-)-oxysporidinone (19) and two of its new analogues, (-)-4,6'anhydrooxysporidinone (20) and (-)-6-deoxyoxysporidinone (21) (Fig. 4). MTT assay-guided fractionation of the ethyl acetate extract of a liquid culture of F. oxysporum strain CECIS led to the isolation of rhodolamprometrin (22), bikaverin (23), and the new natural product, 6-deoxybikaverin (24) (Fig. 4). Compounds 18 $\mathbf{2 4}$ were evaluated for in vitro cytotoxic activity against a panel of four sentinel human cancer cell lines, NCI-H460 (non-small cell lung), MIAPaCa-2 (pancreatic carcinoma), MCF-7 (breast), and SF-268 (CNS glioma) and only beauvericin (18) and bikaverin (23) were found to be cytotoxic. Beauvericin (18) showed selective activity towards non-small cell lung cancer (NCI-H460) cell line, whereas bikaverin (23) was found to be more toxic to the pancreatic carcinoma (MIAPaCa-2) cell line. Interestingly, 6-deoxybikaverin (24) which lacks the $\mathrm{OH}$ group at C-6 did not exhibit any cytotoxic activity towards any of the cell lines used even at concentrations of $4.0 \mu \mathrm{g} / \mathrm{mL}$. As beauvericin (18) was isolated using WHA-guided fractionation, it was evaluated for cell migration inhibitory activity in two metastatic cancer cell lines, PC-3M (prostate cancer) and MDA-MB-231 (breast cancer), and was found to inhibit their migration at concentrations ranging from $2.0-2.5$ and $3.0-4.0 \square \mathrm{M}$, respectively. The concentrations of beauvericin required for $50 \%\left(\mathrm{IC}_{50}\right)$ and $25 \%$ $\left(\mathrm{IC}_{25}\right)$ inhibition of PC-3M cell proliferation/survival as measured by the MTT assay at $20 \mathrm{~h}$ (time used for WHA with PC-3M) were determined to be 3.8 and $2.3 \square \mathrm{M}$, respectively, and those for MDA-MB-231 at $40 \mathrm{~h}$ (time used for WHA with MDA-MB231) were found to be 7.5 and $6.4 \square \mathrm{M}$, respectively, suggesting that it is capable of inhibiting migration of both metastatic cancer cell lines at sub-lethal concentrations. Encouraged by this observation we next evaluated the antiangiogenic activity of beauvericin by assessing its ability to interfere with endothelial cell network formation (Meade-Tollin et al. 2004). Beauvericin clearly showed potent anti-angiogenic activity at sub-lethal concentrations, as demonstrated by the inhibition of HUVEC-2 endothelial cell network formation.

\section{ACKNOWLEDGEMENTS}

Financial support for this work was generously provided by the U.S. National Institutes of Health through the National Cancer Institute (Grant R01 CA90265), and the Arizona Biomedical Research Commission.

\section{REFERENCES}

Bashyal, B.P.; Wijeratne, E.M.K.; Faeth, S.H.; Gunatilaka, A.A.L. 2005. Globosumones A - C, cytotoxic orsellinic acid esters from the Sonoran desert endophytic fungus Chaetomium globosum. Journal of Natural Products 68: 724- 728.

Bush, L.P.; Wilkinson, H.H.; Schardl, C.L. 1997. Bioprotective alkaloids of grass-fungal endophyte symbioses. Plant Physiology 114: 1- 7 .

Chapela, I.H. 1989. Fungi in healthy stems and branches of American beech and aspen: a comparative study. New Phytologist 113: 65- 75.

Clay, K.; Holah, J. 1999. Fungal endophyte symbiosis and plant diversity in successional fields. Science 285: 1742- 1744.

Eyberger, A.L.; Dodapati, R.; Porter, J.R. 2006. Endophyte fungal isolates from Podophyllum peltatum produce podophyllotoxin. Journal of Natural Products 69: 1121- 1124.

Faeth, S.H.; Hammon, K.E. 1997. Fungal endophytes in oak trees. Long-term patterns of abundance and associations with leafminers. Ecology 78 : 810- 819.

Gunatilaka, A.A.L.; Kingston, D.G.I. 1998. DNA-Damaging natural products with potential anticancer activity. pp. 457- 505. In: Studies in Natural Products Chemistry, Vol. 20, Structure and Chemistry (Part F). Ed. Atta-ur-Rahman. Elsevier, Amsterdam.

Gunatilaka, A.A.L. 2006. Natural products from plant-associated microorganisms: distribution, structural diversity, bioactivity, and implications of their occurrence. Journal of Natural Products 69: 509- 506.

Meade-Tollin, L.C.; Wijeratne, E.M.K.; Cooper, D.; Guild, M.; Jon, E.; Fritz, A.; Zhou, G-X.; Whitesell, L.; Liang, JY.; Gunatilaka, A.A.L. 2004. Ponicidin and oridonin are responsible for the antiangiogenic activity of Rabdosia rubescens, a constituent of the herbal supplement PC SPES, Journal of Natural Products 67: 2- 4.

Puri, S.C.; Verma, V.; Amna, T.; Qazi, G.N.; Spiteller, M. 2005. An endophytic fungus from Nothapodytes foetida that produces camptothecin. Journal of Natural Products 68: 1717- 1719.

Schulthess, F.; Faeth, S.H. 1998. Distribution, abundances, and associations of the endophytic fungal community of Arizona fescue (Festuca arizonica). Mycologia 90: 569- 578.

Stierle, A.; Strobel, G.; Stierle, D. 1993. Taxol and taxol production by Taxomyces andreanae, an endophytic fungus of Pacific yew. Science 260: 214- 216.

Stierle, A.; Strobel, G.; Stierle, D.; Grothahaus, P.; Bignami, G.. 1995. The search for a taxol-producing microorganism among the edophytic fungi of the Pacific yew, Taxus brevifolia. Journal of Natural Products 58: 1315- 1324.

Strobel, G.A.; Hess, W.M.; Ford, E.; Sidhu, R.S.; Yang, X. 1996. 
Taxol from fungal endophytes and the issue of biodiversity. Journal of Industrial Microbiology 17: 417- 423.

Suryanarayanan, T.S.; Wittlinger, S.; Faeth, S.H. 2005. Endophytic fungi associated with cacti of Arizona. Mycological Research 109: 635- 639.

Turbyville, T.J.; Wijeratne, E.M.K.; Liu, M.X.; Burns, A.M., Seliga, C.J.; Luevano, L.A.; David, C.L.; Faeth, S.H.; Whitesell, L.; Gunatilaka, A.A.L. 2006. Search for Hsp90 inhibitors with potential anticancer activity: isolation and SAR studies of radicicol and monocillin I from two plantassociated fungi of the Sonoran desert. Journal of Natural Products 69: 178- 184.

Wijeratne, E.M.K.; Paranagama, P. A.; Gunatilaka, A.A.L. 2006. Five new isocoumarins from Sonoran desert plantassociated fungal strains Paraphaeospaeria quadriseptata and Chaetomium chiversii. Tetrahedron 62: 8439- 8446. 